\title{
157. Two Cases of Sexual Abnormalities in Homoeogryllus japonicus de Haan.
}

\author{
By Kazuo Suzukr. \\ Botanical Institute, Faculty of Agriculture, Tokyo Imperial University. \\ Komaba, Tokyo.
}

(Comm. by C. IshikawA, M.I.A., Nov. 13, 1933.)

Various cases of sexual abnormalities are described by Dr. F. Omachi, both in the present species as well as in other species of the Grylloid Family ('27, '29, \& '32) ' $^{1}$ and their origins discussed. To these the writer wishes to add two more cases obtained from insects treated with X-rays, the X-ray treatment was carried out as follows:-

Kilovolts........................ 70 .

Mileampers $\quad \ldots \ldots \ldots \ldots \ldots \ldots \ldots . . . . . .6$

Distance from the target ..... 30 c.m.

Aluminium filter .............. 1 m.m.

Time exposure ................ 5 minutes.

The insects used for experiments were divided into groups of A, B $\&$ C.

In A group, the female larvae of about 3-4 weeks after the hatching were exposed to X-ray, and the female insects from these larvae were crossed with untreated normal males.

In B group, the male larvae were similarly treated, whereas in group $\mathrm{C}$, both untreated males and females were crossed, and were reared as controls.

The results of the experiments are shown in the table here appended :-

1) Proc. Imp. Academy.

27,-3 Preliminary Note on a Grynandromorph Madasumma mormorato.

'29,-5 Preliminary Note on a Special type of Sex-abnormality in Homoeogryllus japonicus, de Haan (Oecanthidae).

'32,-8 Preliminary Note on Breeding Experiments with male Intersexes in Homoeogryllus japonicus de Haan. 
No. 9.] Two Cases of Sexual Abnormalities in Homoeogryllus japonicus de Haan.

549

\begin{tabular}{|c|c|c|c|c|c|c|c|}
\hline \multicolumn{4}{|c|}{$1932 \mathrm{P}}$. & \multicolumn{4}{|c|}{1933 Fl. } \\
\hline & Females & Males & $\begin{array}{l}\text { Mum of } \\
\text { eggs laid }\end{array}$ & 甲 & $\delta$ & $\begin{array}{l}\text { Sex abnor- } \\
\text { mality }\end{array}$ & Total \\
\hline Group A & X. 9 & N. $\delta$ & 6651 & 2060 & 1960 & 1 & 4021 \\
\hline Group B & N. $\%$ & X. $\delta$ & 11548 & 3048 & 3536 & 1 & 6585 \\
\hline Group C & N. +9 & N. $\delta$ & 3282 & 1028 & 1120 & 0 & 2148 \\
\hline
\end{tabular}

$\mathrm{N}+=$ Normal female,

$\mathrm{N} s=$ Normal male,

$\mathrm{X}+=\mathrm{x}$-rayed female, $\quad \mathrm{X} \delta=\mathrm{x}$-rayed male.

It will be seen that in each of A \& B groups, a single specimen was obtained which shows the following abnormalities.

The insect of A group is characterised externally by the presence of male features on the left, and those of female on the right. These extend not only the general outline of the body, but also the external genital organs, as' will be seen in figures 1 and 2 , plate.

The insects of the $\mathrm{B}$ group, has a male, the fore wing on the left side, which is somewhat smaller than in normal male specimens. but the wing of the right side is of a normal female type, while external genital organs are masculine (Fig. 3, plate).

The histological examination of the reproductive organ shows that the right organ is a typical ovary, while that of the left contains eggs and spermatozoa in different follicles. (Text Fig.).

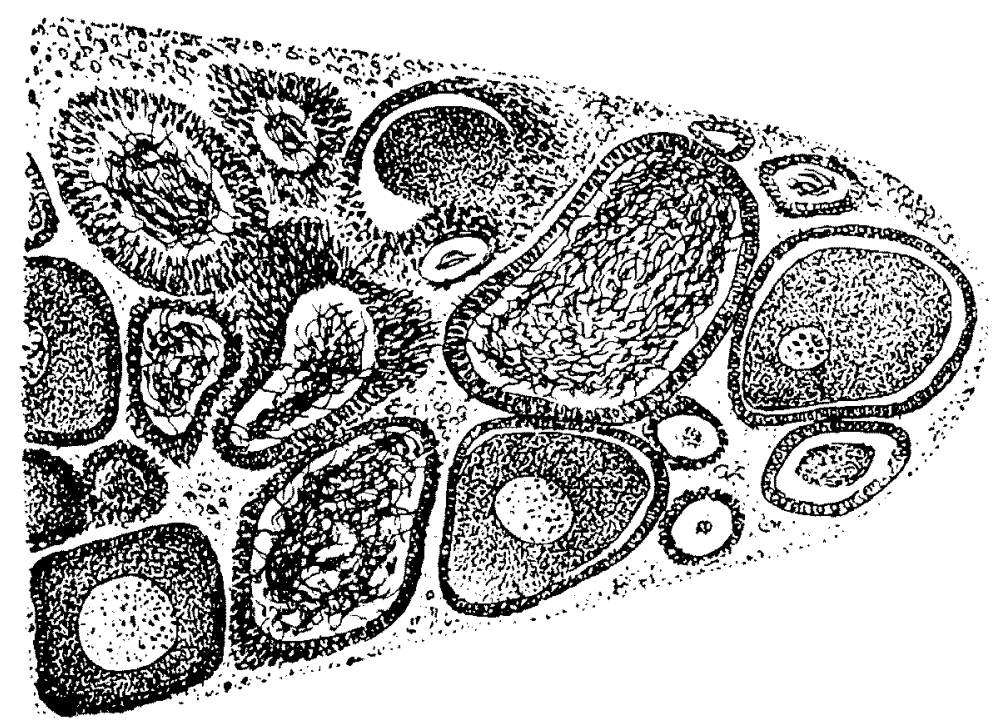

Text Figure. Section, Left intersexual organ of Fig. 3, Plate. Leitz objective 5 , ocular 3 . 
Thus it will be seen that the abnormal specimen of the A group is a gynandromorph, while that of the $\mathrm{B}$ group is an intersex. The two abnormal specimens are as above stated, produced from those treated with $\mathrm{x}$-rays, while all the controls have shown the normal characters, it may be conjectured that these are the results of the x-ray.

But since the number of the specimens are so small, and since, moreover, sexual abnormalities occur in insect of Grylloid family in the absence of the x-ray treatment, the present cases can most probably not be accounted for as the result of such a treatment. Even so, it will, however, be of interst as an additional case of such abnormalities found among the insects of the family in which Dr. Omachi has found so many interesting cases.

Further investigations which are being carried on by the writer may perhaps bring out some conclusive facts about the influence of the x-ray treatment on the formation of sexual abnormalities.

The writer wishes to express his gratitude to Professor K. Miyake and Professor K. Masui for their invaluable advices and criticisms. Thanks are also due to a grant from Matukata fund by which the present investigation was made possible.

\section{Explanation of Plants.}

Fig. 1. Gynandromorph. End of abdomen with ovipositor placed somewhat ventrally on right side; left half of male genital organ, somewhat deformed.

Fig. 2. Same from left side. Dorsal portion which represents left male sexual organ is somewhat deformed, while ventral portion which has shape of ovipositor, rudimentary, placed rather on left side.

Fig. 3. Intersex. Left wing, male, somewhat smaller than normal. Right wing, normal female. External genital organ, normal male. 


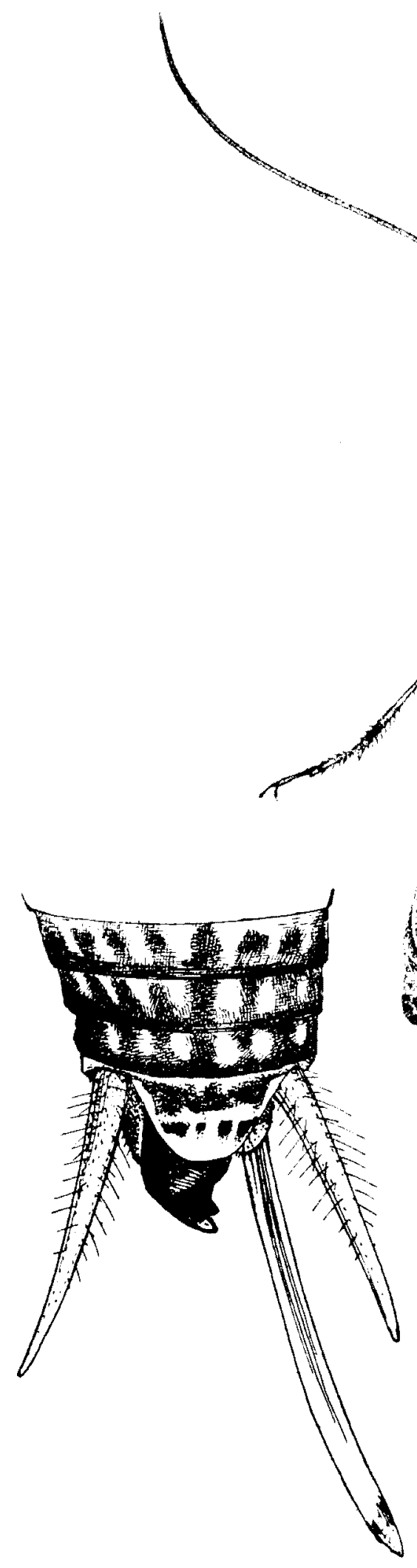

Fig. 1.
Fig. 2.
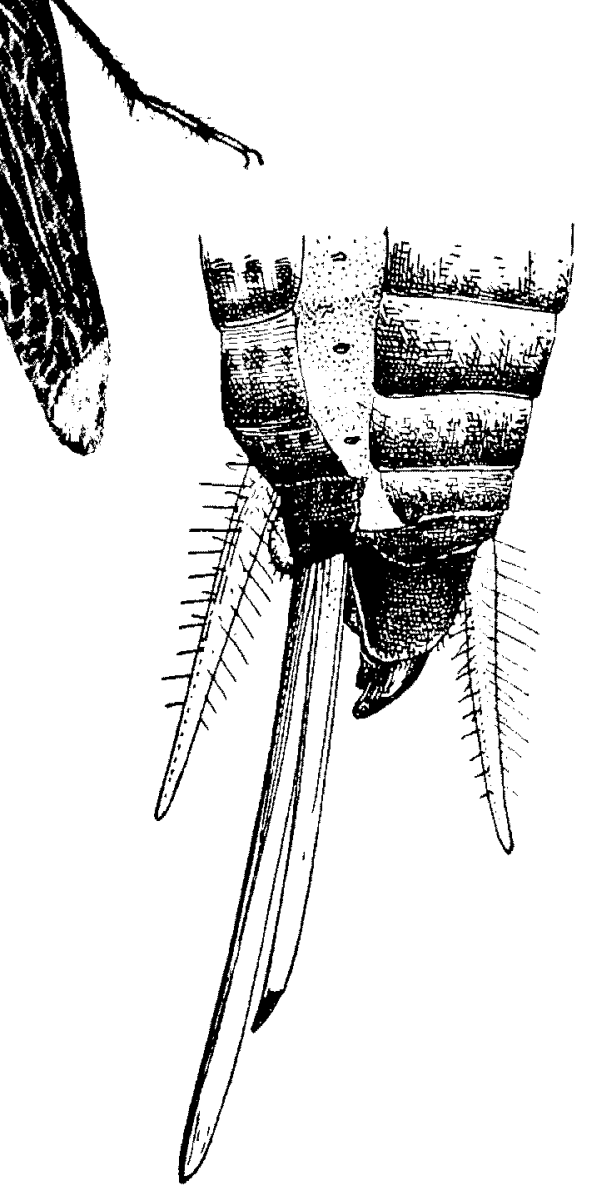

Fig. 3. 